\title{
EDITORIAL
}

\section{Vittalle 35 anos: panorama e novos desafios}

Em 2020, a Vittalle - Revista de Ciências da Saúde completa 35 anos de existência e contribuição científica no âmbito das Ciências da Saúde e áreas afins. São 32 volumes publicados, ao longo desses anos, contendo artigos que contemplam as mais diversas temáticas e que contribuem para o avanço do conhecimento científico.

Nos últimos anos a Revista vem passando por diversas mudanças, que tem refletido no crescimento do periódico em âmbito nacional e até internacional. Em 2020, destaca-se a atualização do corpo editorial, com a inclusão de pesquisadores de diferentes regiões do Brasil e de outros países, e uma maior abrangência de áreas dentro das Ciências da Saúde e áreas afins, incluindo pesquisadores das áreas da Medicina, Enfermagem, Farmácia, Ciências Biológicas, Odontologia, Fisioterapia, Nutrição, Psicologia entre outras. Além disso, a maior divulgação do periódico, redução no tempo de avaliação dos artigos e comprometimento com os prazos de publicação, contribuíram para o aumento no número de submissões e de artigos publicados.

O crescimento da revista pode ser exemplificado observando-se o número de artigos publicados nos últimos cinco anos. Em 2015 e 2016, foram publicados 6 e 10 artigos, respectivamente, em apenas um número por ano. Nos anos seguintes, observa-se um incremento, sendo 20 artigos em 2017, 26 em 2018, e 19 em 2019, publicados em dois números por ano. Já em 2020, foram 68 artigos publicados, refletindo um aumento de aproximadamente três vezes em relação à média dos três anos anteriores. Além do quantitativo de artigos, destaca-se a maior abrangência do periódico. Até 2019, as publicações eram provenientes majoritariamente das regiões Sul e Sudeste, e em menor número da região Nordeste. Em 2020, esse perfil mudou e o periódico recebeu artigos de todas as regiões brasileiras, contemplando 18 estados, além de dois artigos de países estrangeiros de língua portuguesa, Portugal e Moçambique (Figura 1). Este aspecto contribui para a diminuição da endogenia do período, fator que é considerado essencial pelos indexadores e para a qualificação da revista.

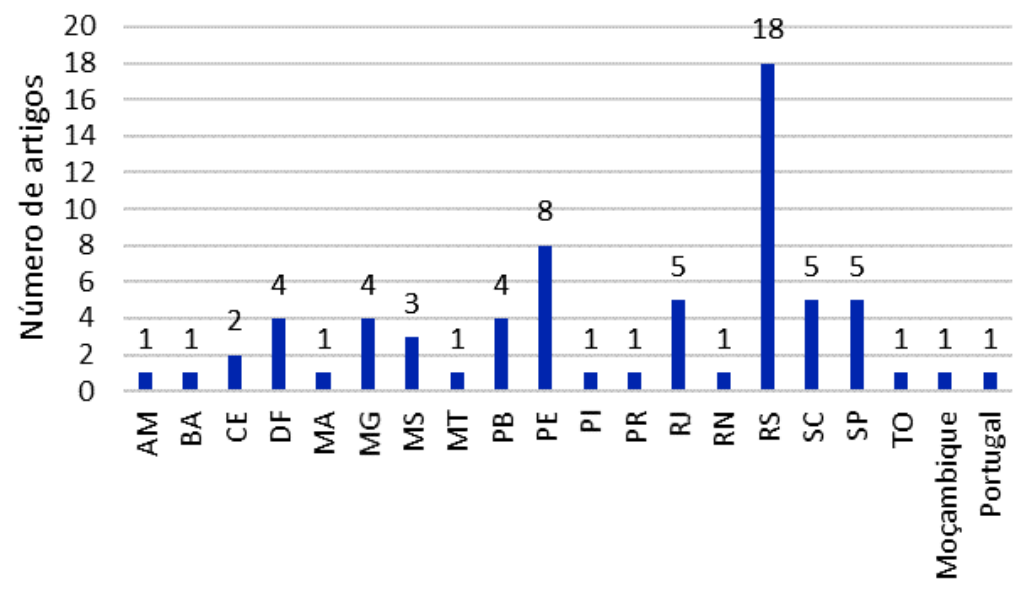

Figura 1 - Distribuição dos artigos publicados na Vittalle - Revista de Ciências da Saúde por Estados e países em 2020.

Outro aspecto que reflete o crescimento da Revista é o número de citações dos artigos no Google Acadêmico. Como pode ser observado na Figura 2, este número vem crescendo significativamente nos últimos anos, o que reforça a maior abrangência e 
destaque das publicações. A publicação de um maior número de artigos em língua inglesa é um dos fatores que têm contribuído para um maior número de citações, inclusive em revistas internacionais.

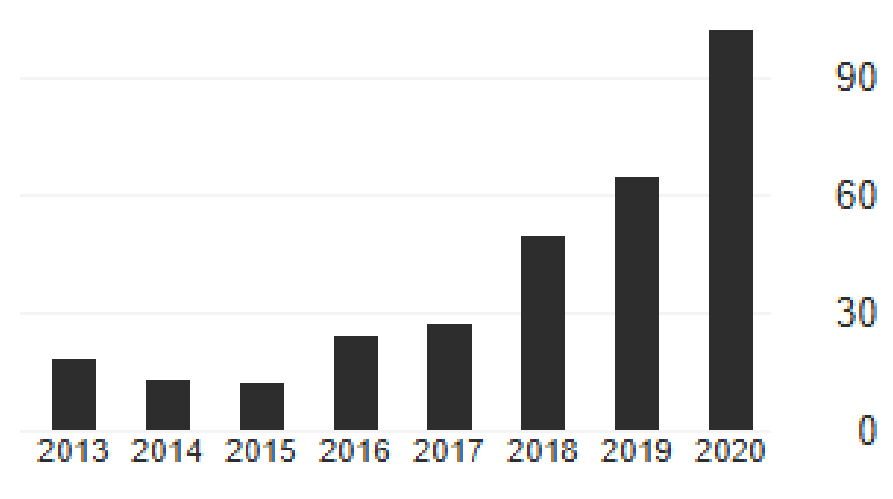

Figura 2 - Número de citações dos artigos publicados na Vittalle - Revista de Ciências da Saúde no período de 2013 a 2020. Fonte: https://scholar.google.com.br/citations?user=kz211MsAAAAJ\&hl=pt-BR. Acesso em 02/12/2020.

É indiscutível que a Revista vem crescendo ao longo dos últimos anos, resultado de um corpo editorial comprometido e diversificado, e do espaço e prestígio que vêm ganhando entre os pesquisadores de diferentes Instituições. O apoio Institucional, especialmente da Faculdade de Medicina e da Pró-Reitoria de Extensão e Cultura, bem como a atuação da Editora da FURG, tem sido essencial para a manutenção do periódico e seus avanços recentes. Esse crescimento não pode parar e o corpo editorial segue trabalhando por melhorias. A indexação em novas bases de dados, a obtenção de recursos financeiros, a atração de novas submissões, a implementação da nova plataforma da revista, a atração de novos pareceristas e a internacionalização são alguns dos desafios da Vittalle para os próximos anos.

Prof $^{\text {a. }}$ Dr $^{\text {a. }}$ Mariana Appel Hort

Editora-chefe da Vittalle - Revista de Ciências da Saúde Professora adjunta do Instituto de Ciências Biológicas

Universidade Federal do Rio Grande - FURG 